University of Wollongong

Research Online

Faculty of Engineering and Information

Faculty of Engineering and Information

Sciences - Papers: Part A

Sciences

$1-1-2013$

Impact of humic acid fouling on membrane performance and transport of pharmaceutically active compounds in forward osmosis

Ming Xie

University of Wollongong, mx504@uowmail.edu.au

Long D. Nghiem

University of Wollongong, longn@uow.edu.au

William E. Price

University of Wollongong, wprice@uow.edu.au

Menachem Elimelech

Yale University

Follow this and additional works at: https://ro.uow.edu.au/eispapers

Part of the Engineering Commons, and the Science and Technology Studies Commons

Research Online is the open access institutional repository for the University of Wollongong. For further information contact the UOW Library: research-pubs@uow.edu.au 


\title{
Impact of humic acid fouling on membrane performance and transport of pharmaceutically active compounds in forward osmosis
}

\begin{abstract}
The impact of humic acid fouling on the membrane transport of two pharmaceutically active compounds (PhACs) - namely carbamazepine and sulfamethoxazole - in forward osmosis (FO) was investigated. Deposition of humic acid onto the membrane surface was promoted by the complexation with calcium ions in the feed solution and the increase in ionic strength at the membrane surface due to the reverse transport of $\mathrm{NaCl}$ draw solute. The increase in the humic acid deposition on the membrane surface led to a substantial decrease in the membrane salt $(\mathrm{NaCl})$ permeability coefficient but did not result in a significant decrease in the membrane pure water permeability coefficient. As the deposition of humic acid increased, the permeation of carbamazepine and sulfamethoxazole decreased, which correlated well with the decrease in the membrane salt $(\mathrm{NaCl})$ permeability coefficient. It is hypothesized that the hydrated humic acid fouling layer hindered solute diffusion through the membrane pore and enhanced solute rejection by steric hindrance, but not the permeation of water molecules. The membrane water and salt $(\mathrm{NaCl})$ permeability coefficients were fully restored by physical cleaning of the membrane, suggesting that humic acid did not penetrate into the membrane pores.
\end{abstract}

\section{Keywords}

performance, fouling, acid, transport, humic, impact, pharmaceutically, active, membrane, compounds, osmosis, forward

\section{Disciplines \\ Engineering | Science and Technology Studies}

\section{Publication Details}

Xie, M., Nghiem, L. D., Price, W. E. \& Elimelech, M. (2013). Impact of humic acid fouling on membrane performance and transport of pharmaceutically active compounds in forward osmosis. Water Research, 47 (13), 4567-4575. 
1 Impact of humic acid fouling on membrane performance and transport of pharmaceutically active compounds in forward osmosis

Ming Xie ${ }^{1}$, Long D. Nghiem ${ }^{1, *}$, William E. Price ${ }^{2}$, and Menachem Elimelech ${ }^{3}$

${ }^{1}$ Strategic Water Infrastructure Laboratory, School of Civil, Mining and

8 Environmental Engineering, University of Wollongong, Wollongong, NSW 2522, 9 Australia

${ }^{2}$ Strategic Water Infrastructure Laboratory, School of Chemistry, University of

$12{ }^{3}$ Department of Chemical and Environmental Engineering, Yale University, New 13 Haven, CT 06520-8286, USA 


\section{Abstract}

The impact of humic acid fouling on the membrane transport of two pharmaceutically 18 active compounds (PhACs) - namely carbamazepine and sulfamethoxazole - in forward 19 osmosis (FO) was investigated. Deposition of humic acid onto the membrane surface was promoted by the complexation with calcium ions in the feed solution and the increase in ionic strength at the membrane surface due to the reverse transport of $\mathrm{NaCl}$ draw solute. The increase in the humic acid deposition on the membrane surface led to a substantial decrease in the membrane salt $(\mathrm{NaCl})$ permeability coefficient but did not result in a significant decrease in the membrane pure water permeability coefficient. As the deposition of humic acid increased, the permeation of carbamazepine and sulfamethoxazole decreased, which correlated well with the decrease in the membrane salt $(\mathrm{NaCl})$ permeability coefficient. It is hypothesized that the hydrated humic acid fouling layer hindered solute diffusion through the membrane pore and enhanced solute rejection by steric hindrance, but not the permeation of water molecules. The membrane water and salt $(\mathrm{NaCl})$ permeability coefficients were fully restored by physical cleaning of the membrane, suggesting that humic acid did not penetrate

31 into the membrane pores.

32 Keywords: forward osmosis; pharmaceutically active compounds (PhACs); calcium; humic 33 acid; natural organic matter; fouling. 


\section{Introduction}

A large proportion of the world's population lives in areas with severe water shortages. This problem is being further exacerbated by urbanisation, population growth, and climate change. As a result, over the last few decades, significant efforts have been made to develop innovative treatment processes that utilise alternative water sources such as seawater and reclaimed wastewater in order to ensure a secure and reliable supply of clean drinking water that is independent of the hydrological cycle. Notable progress can be seen in the field of membrane filtration technologies. For example, seawater desalination and wastewater reuse by reverse osmosis (RO) and nanofiltration (NF) membrane filtration have been widely used to augment the freshwater supply in many parts of the world (Elimelech and Phillip 2011, Shannon et al. 2008). Forward osmosis (FO), which is a membrane-based filtration process, is still emerging but has the potential to advance water and wastewater treatment (Cath et al. 2006, Zhao et al. 2012). Compared to the NF and RO processes, FO has a much smaller fouling propensity (Mi and Elimelech 2008). Instead of hydraulic pressure, FO utilises the osmotic pressure of a highly concentrated draw solution as the driving force to transfer water from the feed solution to the draw solution through a dense polymeric membrane. As a result, FO can potentially be employed as a pre-treatment for the NF/RO processes (Hoover et al. 2011, Shaffer et al. 2012, Yangali-Quintanilla et al. 2011) or in combination with a membrane bioreactor (Achilli et al. 2009, Alturki et al. 2012) to extract clean water from wastewater and other alternative water sources.

The occurrence of chemicals of emerging concern, particularly pharmaceutically active compounds (PhACs), in wastewater and secondary treated effluent at trace levels is a major issue associated with wastewater reuse, particularly when intended for potable purposes (Basile et al. 2011, Carballa et al. 2004, Schwarzenbach et al. 2006). Several recent studies have investigated the removal of PhACs by FO. These studies reveal that the removal mechanisms of PhACs by FO membranes are governed by several factors, including membrane interfacial properties (Jin et al. 2012a), physicochemical properties of the solutes (Alturki et al. 2013, Hancock et al. 2011b, Valladares Linares et al. 2011) and solution chemistry (Xie et al. 2012b). However, the current state-of-the-art understanding of PhAC rejection behaviour in the FO process is still limited. In particular, little is known about the impact of membrane fouling on the rejection of PhACs.

The effect of membrane fouling on the rejection of PhACs has been investigated extensively in NF and RO processes. These studies suggest that membrane fouling influences 
the rejection of PhACs via modification of membrane surface charge (Plakas et al. 2006, Xu et al. 2006), pore blockage (Nghiem and Hawkes 2007) or cake enhanced concentration polarization ( $\mathrm{Ng}$ and Elimelech 2004, Vogel et al. 2010), thereby either improving or reducing their rejection. By drawing on these well-established mechanisms in NF and RO processes, several studies have also been initiated to shed light on the impact of membrane fouling on the rejection of PhACs in FO. Hancock et al. (2011b) observed that rejection of PhACs by the FO process substantially increased when the membrane was fouled by wastewater effluent in a pilot-scale setup. Valladares Linares et al. (2011) proposed that the fouling layer altered the charge and hydrophobicity of the FO membrane surface, thereby enhancing the rejection of ionic and neutral PhACs. Jin et al. (2012b) highlighted the enhanced membrane sieving effect by membrane fouling when they compared the rejections of boron and arsenate by an alginate-fouled FO membrane.

In FO, for a non-ideal membrane with less than $100 \%$ solute rejection, the water flux is coupled with a reverse permeation of the draw solute. Recently, several studies were conducted to understand this mechanism (Hancock and Cath 2009, Xie et al. 2012a) and to quantify this bi-directional mass transfer (Hancock et al. 2011a, Phillip et al. 2010, Yong et al. 2012). Specifically, membrane fouling could be affected by the reverse permeation of draw solutes. Boo et al. (2012) reported that reverse permeation of draw solutes promoted colloidal aggregation, which enhanced membrane fouling and reduced fouling reversibility by simple physical cleaning. As a result, it is of practical interest to understand the role of reverse permeation of draw solutes on membrane fouling and its associated effect on the rejection of PhACs.

The aim of this study is to investigate the impact of humic acid fouling on the membrane permeation of two model PhACs (i.e. sulfamethoxazole and carbamazepine) in forward osmosis. Fouling and PhAC flux through the membrane were investigated under different calcium ion concentrations and a variety of draw solutions. Key membrane properties, and forward hydrogen ion and reverse salt fluxes were measured to elucidate the impact of humic acid fouling on the permeation of PhACs. Mechanisms accounting for the impact of humic acid fouling on PhAC permeation were systematically proposed and delineated. 


\section{Materials and methods}

98

99

100

101

102

103

104

105

106

107

108

109

110

111

112

113

114

115

116

117

118

119

120

121

122

123

\subsection{Forward osmosis membrane}

An asymmetric cellulose-based membrane specifically designed for FO applications was supplied by Hydration Technology Innovations (Albany, OR). While detailed composition of the membrane is proprietary, it is believed that it has a dense cellulose triacetate active layer embedded in a polyester mesh. Further details about this FO membrane are available elsewhere (Cath et al. 2006, McCutcheon and Elimelech 2008).

\subsection{Determination of water and salt ( $\mathrm{NaCl}$ ) permeability coefficients}

Water permeability coefficient $(A)$ and salt $(\mathrm{NaCl})$ permeability coefficient $(B)$ were determined using a standard method recently established by Cath et al. (2013). Briefly, the measurement was conducted in RO mode using a laboratory scale cross-flow filtration system. Prior to each measurement, the membrane was compacted at 15 bar using deionised water for at least 12 hours until a constant permeate water flux had been obtained. The water permeability coefficient was determined by dividing the pure water permeate flux obtained at 10 bar (145 psi) using deionised water as the feed by the applied hydraulic pressure. $\mathrm{NaCl}$ was then added to the feed solution to obtain a concentration of $2000 \mathrm{mg} / \mathrm{L}$ in order to determine the salt $(\mathrm{NaCl})$ permeability coefficient at 10 bar (145 psi). The RO system was stabilised for two hours before the permeate water flux ( $\left.J_{w}^{\mathrm{NaCl}}\right)$ was recorded and feed and permeate samples were taken to determine the observed $\mathrm{NaCl}$ rejection value $\left(R_{o}\right)$. The observed salt $(\mathrm{NaCl})$ rejection, $R_{0}$, was calculated from the difference between the bulk feed $\left(c_{\mathrm{b}}\right)$ and permeate $\left(c_{\mathrm{p}}\right)$ salt concentrations, $R_{o}=1-c_{\mathrm{p}} / c_{\mathrm{b}}$. The $B$ value was determined from (Cath et al. 2013):

$$
B=J_{w}^{N a C l}\left(\frac{1-R_{o}}{R_{o}}\right) \exp \left(-\frac{J_{w}^{N a C l}}{k_{f}}\right)
$$

where $k_{\mathrm{f}}$ is the mass transfer coefficient for the cross-flow channel of the RO membrane cell.

The mass transfer coefficient $\left(k_{\mathrm{f}}\right)$ was experimentally determined using the film theory (Sutzkover et al. 2000):

$$
k_{f}=\frac{J_{\text {salt }}}{\ln \left[\frac{\Delta P}{\pi_{b}-\pi_{p}}\left(1-\frac{J_{\text {salt }}}{J_{w}}\right)\right]}
$$


where $\pi_{\mathrm{p}}$ and $\pi_{\mathrm{b}}$ are the osmotic pressures of the permeate and $2000 \mathrm{mg} / \mathrm{L} \mathrm{NaCl}$ feed solution, respectively; $\Delta \mathrm{P}$ is the applied pressure; and $J_{\mathrm{w}}$ and $J_{\text {salt }}$ are the pure water flux and the water flux of the $2000 \mathrm{mg} / \mathrm{L} \mathrm{NaCl}$ feed solution, respectively.

To measure the membrane pure water and salt $(\mathrm{NaCl})$ permeability coefficient in the presence of a humic acid fouling layer, the membrane was pre-fouled with a feed solution of $50 \mathrm{mg} / \mathrm{L}$ humic acid and a calcium concentration varying between 0 and $4 \mathrm{mM}$ at 10 bar (145 psi) for 10 hours. The membrane pure water and salt $(\mathrm{NaCl})$ permeability coefficients were then measured using the same protocol as described above.

\subsection{Zeta potential measurement}

The membrane zeta potential was determined using a streaming current electrokinetic analyser (SurPASS, Anton Paar GmbH, Austria). The zeta potential was calculated from the measured streaming potential data using the Fairbrother-Mastin method (Elimelech et al. 1994). Streaming potential measurement was conducted in a background electrolyte solution containing $10 \mathrm{mM} \mathrm{KCl}$. The same electrolyte solution was used to flush the cell thoroughly prior to automatic $\mathrm{pH}$ titration using either hydrochloric acid (1 M) or potassium hydroxide (1 M). All measurements were performed at room temperature (approximately $22{ }^{\circ} \mathrm{C}$ ), which was monitored by the temperature probe of the instrument.

Prior to the zeta potential measurement, the humic acid fouled membranes were dried in a desiccator. The dried membranes were then soaked in Milli-Q water for 24 hours prior to the measurement. A small amount of humic acid was released into the solution and the rest was stable on the membrane surface. This procedure effectively prevents the removal of the humic acid fouling layer due to hydrodynamic shear stress during the streaming potential measurement (Simon et al. 2011).

\subsection{Chemical reagents}

Analytical grade sulfamethoxazole and carbamazepine were purchased from Sigma149 Aldrich (St. Louis, MO) and used as model PhACs. They are active ingredients of pharmaceutical products and have been frequently detected at trace levels in secondary treated effluents and sewage-impacted water bodies (Schwarzenbach et al. 2006). Their molecular structures and key physicochemical properties are summarised in Table 1. At the experimental $\mathrm{pH}$ of 6.5 , sulfamethoxazole is negatively charged due to the dissociation of its amine functional group, while carbamazepine is neutral. A stock solution of $2 \mathrm{~g} / \mathrm{L}$ was 
obtained by dissolving these two compounds in pure methanol. The stock solution was stored at $-18{ }^{\circ} \mathrm{C}$ in the dark and was used within one month.

\section{[Table 1]}

Humic acid (Sigma-Aldrich, St. Louis, MO) was selected as a model organic foulant. Humic acid stock solution (10 g/L) was prepared by dissolving the humic acid powder as received in Milli-Q water and adjusting the $\mathrm{pH}$ to 8.2 with $\mathrm{NaOH}$ to ensure complete dissolution. The stock solution was stored in a sterilized amber glass bottle at $4{ }^{\circ} \mathrm{C}$ and was used within one month.

\subsection{Forward osmosis setup}

A bench-scale flat-sheet cross-flow FO system described in our previous publication (Xie et al. 2012b) was used (Supplementary Data, Figure S1). The membrane cell had two identical and symmetrical flow chambers with a length, width and channel height of 130, 95, and $2 \mathrm{~mm}$, respectively. The membrane sample was inserted between the two chambers to separate the feed solution from the draw solution. The total effective membrane area for mass transfer was $123.5 \mathrm{~cm}^{2}$.

Two variable speed gear pumps (Micropump, Vancouver, WA) were used to circulate the feed and draw solutions. Flow rates of the feed and draw solutions were monitored using two rotameters and kept constant at $1 \mathrm{~L} / \mathrm{min}$ (corresponding to a cross-flow velocity of 9 $\mathrm{cm} / \mathrm{s}$ ). The draw solution reservoir was placed on a digital balance (Mettler-Toledo Inc., Hightstown, NJ) and weight changes were recorded by a computer to calculate the permeate flux. The conductivity of the draw solution was continuously measured using a conductivity probe (Cole-Parmer, Vernon Hills, IL). To maintain constant draw solution concentration, a peristaltic pump was regulated by a conductivity controller to intermittently dose a small volume of a concentrated draw solution (6 $\mathrm{M} \mathrm{NaCl}$ or $4 \mathrm{M} \mathrm{MgSO}_{4}$, depending on the type of draw solution) into the draw solution reservoir (control accuracy was $\pm 0.1 \mathrm{mS} / \mathrm{cm}$ ). The concentrated draw solution makeup reservoir was also placed on the same digital balance. This setup ensured that the transfer of liquid between the two reservoirs did not interfere with the measurement of permeate water flux and that the system could be operated at a constant osmotic pressure driving force during the experiment. Manual control of draw solution concentration was applied when neutral glucose and urea were used as draw solutes in the FO experiment. A concentrated glucose (6 M) or urea (6 M) solution was manually added into 
the draw solution reservoir every two hours to avoid the dilution of the draw solution and the decline of osmotic pressure driving force.

\subsection{Membrane fouling protocol}

In all FO experiments, the initial volumes of feed and draw solutions were $4 \mathrm{~L}$ and 1 L, respectively. A new membrane sample was used for each experiment. Mass concentrations of humic acid and each PhAC in the feed solution $(20 \mathrm{mM} \mathrm{NaCl}$ and $1 \mathrm{mM} \mathrm{NaHCO}$ ) were $50 \mathrm{mg} / \mathrm{L}$ and $500 \mu \mathrm{g} / \mathrm{L}$, respectively. The concentration of $\mathrm{CaCl}_{2}$ varied from 0 to $4 \mathrm{mM}$ in the feed solution. Approximate $2 \mathrm{~mL}$ of feed and draw solution samples were taken at specific time intervals for HPLC analysis to determine the concentration of the PhACs, and an 8-mL aliquot sample of the feed was also collected at the same time to measure the humic acid concentration.

Because of the dilution of draw solution and the concentration of feed solution, PhAC permeation $\left(P_{s}\right)$ through the membrane was proposed and employed as an indicator of the impact of the humic acid fouling layer on the permeation of PhACs. $P_{s}$ was calculated by taking into account the draw solution dilution using a mass balance. Because the PhAC permeate concentration in the FO process is diluted by the draw solution, the actual (corrected) concentration of the target solute, $C_{\mathrm{s}(\mathrm{t})}$, can be obtained by taking into account the dilution using a mass balance:

$$
C_{s(t)}=\frac{C_{d s(t)} V_{d s(t)}-C_{d s(t-1)} V_{d s(t-1)}}{V_{w(t)}}
$$

where $V_{\mathrm{w}(\mathrm{t})}$ is the permeate volume of water to the draw solution at time $t ; V_{\mathrm{ds}(\mathrm{t}-1)}$ is the volume of draw solution at time $(t-1) ; V_{\mathrm{ds}(\mathrm{t})}$ is the volume of draw solution at time $t ; C_{\mathrm{ds}(\mathrm{t})}$ is the measured concentration of target solute in the draw solution at time $t$; and $C_{\mathrm{ds}(\mathrm{t}-1)}$ is the measured concentration of target solute in the draw solution at time (t-1). Subsequently, $P_{s}$ is calculated using the actual permeate concentration after accounting for water recovery (i.e., $25 \%$ in all experiments), yielding:

$$
P_{s}=\frac{C_{d s(t)} V_{d s(t)}}{C_{f(0)} V_{f(0)}} 100 \%
$$

where $C_{\mathrm{f}(0)}$ and $V_{\mathrm{f}(0)}$ are the concentrations of the target solute in the feed solution and the volume of feed solution at zero time. 
The reduction in $\mathrm{PhAC}$ permeation $\left(P_{s r}\right)$ was used to evaluate the impact of the humic acid fouling layer on the permeation of PhACs:

$$
P_{s r}=\frac{P_{s-\text { clean }}-P_{s-\text { fouled }}}{P_{s-\text { clean }}} 100 \%
$$

217 where $P_{\text {s-clean }}$ and $P_{\text {s-fouled }}$ are the permeation of PhACs through the clean and humic acid 218 fouled FO membrane, respectively.

219 The reverse flux of draw solute $J_{\text {salt }}$ and forward hydrogen ion flux $J_{H}$ in the FO process were determined using the mass balance calculation:

$$
J_{H} \text { or } J_{\text {salt }}=\frac{\left(C_{t} V_{t}-C_{0} V_{0}\right)}{A t}
$$

where $C_{0}$ and $C_{\mathrm{t}}$ are the concentrations of the draw solute or hydrogen ion in the feed at

223 time 0 and $t$, respectively; $V_{0}$ and $V_{\mathrm{t}}$ are the volumes of the feed at time 0 and $t$, respectively;

$224 A$ is the membrane area, and $t$ is the operating time of the FO experiment. Draw solute 225 concentrations of $\mathrm{NaCl}$ and $\mathrm{MgSO}_{4}$ in the feed solution were determined by measuring electric conductivity and using the calibration curves of $\mathrm{NaCl}$ and $\mathrm{MgSO}_{4}$, while those of glucose and urea were determined using total organic carbon (TOC) measurement. The concentrations of glucose and urea were determined using a TOC analyser (TOC-V $\mathrm{V}_{\mathrm{CSH}}$, Shimadzu, Kyoto, Japan). The hydrogen ion concentration in the feed was determined by the measurement of feed solution $\mathrm{pH}$ value.

The amount of humic acid deposited on the membrane surface was determined using the mass balance calculation:

$$
m_{H A}=\frac{\left(C_{t-H A} V_{t}-C_{0-H A} V_{0}\right)}{A}
$$

234 where $C_{0-H A}$ and $C_{t-H A}$ are the concentrations of humic acid in the feed at time 0 and $t$, respectively. The concentration of humic acid was determined by UV absorbance measurement at $254 \mathrm{~nm}$ using a UV-Vis Spectrophotometer (UV-1700, Shimadzu, Kyoto, Japan). A linear calibration curve with a coefficient of determination $\left(R^{2}\right)$ greater than 0.99

238 between humic acid concentration and $U V_{254}$ absorbance was obtained within the concentration range used in this study. 


\subsection{Analytical methods}

A Shimadzu HPLC system (Shimadzu, Kyoto, Japan), equipped with a Supelco Drug Discovery C18 column (with a diameter, length, and pore size of $4.6 \mathrm{~mm}, 150 \mathrm{~mm}$, and $5 \mu \mathrm{m}$, respectively) and a $U V$-Vis detector, was used to measure the concentration of carbamazepine and sulfamethoxazole in the feed and draw solution samples. The detection wavelength was $280 \mathrm{~nm}$. Milli-Q water buffered with $25 \mathrm{mM} \mathrm{KH}_{2} \mathrm{PO}_{4}$ and acetonitrile were used as the mobile phase at a flow rate of $1 \mathrm{~mL} / \mathrm{min}$. The sample injection volume was 50 $\mu L$. Calibration yielded a linear curve with a coefficient of determination $\left(R^{2}\right)$ above 0.99 . Carbamazepine and sulfamethoxazole analysis was carried out immediately upon the conclusion of each experiment. The limit of quantification for carbamazepine and sulfamethoxazole under these conditions was approximately $10 \mu \mathrm{g} / \mathrm{L}$.

\section{Results and discussion}

\subsection{Impact of fouling on membrane properties}

Deposition of humic acid onto the membrane surface was insignificant when the feed solution contained $50 \mathrm{mg} / \mathrm{L}$ of humic acid and no calcium (Figure 1). As calcium concentration in the feed solution increased from 0 to $4 \mathrm{mM}$, the amount of humic acid deposited on the membrane surface increased significantly from 1.35 to $7.22 \mathrm{mg} / \mathrm{cm}^{2}$. The influence of calcium concentration on the deposition of humic acid onto the membrane surface can be attributed to the complexation between calcium and humic acid molecules (Mi and Elimelech 2008, Nghiem et al. 2008). In fact, visual observation of the membrane samples at the end of each experiment confirmed the proportional increase in humic acid deposition with respect to the increase in calcium concentration (Supplementary Data, Figure S2).

\section{[Figure 1]}

The formation of a humic acid fouling layer on the membrane surface did not result in significant decrease in the membrane pure water permeability coefficient; however, it led to a substantial decrease in the membrane salt $(\mathrm{NaCl})$ permeability coefficient (Figure 2). It is noteworthy that the membrane salt $(\mathrm{NaCl})$ permeability coefficient was measured in $\mathrm{RO}$ mode after the membrane was pre-fouled with humic acid at an initial permeate flux of 6.5 $\mathrm{L} / \mathrm{m}^{2} \mathrm{~h}$ (which is also the flux used in the FO experiments). Under this condition, the deposition of humic acid on the membrane surface could be visually confirmed, but water 
271 flux decline was negligible (Supplementary Data, Figure S2) and the water flux behaviour obtained in the RO mode was similar to that in the FO mode. Therefore, the membrane pure water and salt $(\mathrm{NaCl})$ permeability coefficients of the humic acid fouled membrane obtained in RO mode can be used to assess the impact of the humic acid cake layer on membrane performance in the FO process.

Possessing a large number of free hydroxyl and carboxylic functional groups, the humic acid layer can be highly hydrated (Wang et al. 2001). These hydrated humic acid molecules can block the membrane pores and enhance solute rejection by steric hindrance, which reduces solute transport through the membrane. In the FO process, the transport of water through the membrane is driven mostly by diffusion. This is also true in the RO mode when the permeate flux is sufficiently low. Unlike convective transport, the diffusion of water molecules through the membrane pores is not adversely influenced by a hydrated humic acid layer on the membrane surface, because the hydrated humic acid layer provides more available sites, which facilitate the diffusion of water molecules and thereby, compensate for the blockage of membrane pores (Cohen-Tanugi and Grossman 2012). As a result, the humic acid fouling layer reduced the membrane solute $(\mathrm{NaCl})$ permeability coefficient but did not induce any significant impact on the membrane water permeability coefficient (Figure 2).

\subsection{Impact of fouling on water and reverse salt fluxes}

Generally, the presence of the humic acid fouling layer did not result in any significant FO water flux decline (Figure 3). Using $0.5 \mathrm{M} \mathrm{NaCl}$ as the draw solution, the water flux decreased slightly from 6.5 to $5.1 \mathrm{~L} / \mathrm{m}^{2} \mathrm{~h}$ within the first hour of filtration and remained stable at $5.1 \mathrm{~L} / \mathrm{m}^{2} \mathrm{~h}$ throughout the remaining duration of the experiment. Without humic acid in the feed (denoted as 'clean matrix'), the water flux decline was insignificant. Similarly, no significant water flux decline could be observed even when a discernible humic acid fouling layer formed on the membrane surface at high calcium ion concentrations. This negligible flux decline can be explained by the relatively low water permeate flux and low humic acid fouling layer resistance under the experimental conditions. At a low water permeate flux, the external and internal concentration polarizations are negligible and thus the impact of a humic acid cake layer on permeate flux is expected to be insignificant. Furthermore, the estimated humic acid layer resistance $\left(R_{c}\right)$ was less than $1 \%$ of the 
with a recent study by Parida and Ng (2013) who also reported limited water flux decline when they examined FO fouling using a feed matrix containing up to $50 \mathrm{mg} / \mathrm{L}$ organic foulant and $5 \mathrm{mM}$ calcium.

\section{[Figure 3]}

The formation of a humic acid fouling layer rendered the membrane surface more negatively charged. In addition, the membrane surface became more negatively charged as calcium concentration in the feed solution increased (Figure 4). The increase in membrane negative surface charge could reduce the transport of feed and draw solution ions in the forward and reverse directions. Consequently, at the experimental $\mathrm{pH}$ value of 6.5 , as the calcium concentration in the feed solution increased from 0 to $4 \mathrm{mM}$, the membrane zeta potential changed from -5 to $-38 \mathrm{mV}$ (Figure 4) and the reverse draw salt ( $\mathrm{NaCl}$ ) flux decreased by more than ten-fold, from 3.49 to $0.22 \mathrm{~g} / \mathrm{m}^{2} \mathrm{~h}$ (Figure 1). Ion transport in the FO process is bi-directional (Hancock et al. 2011a); thus, a decrease in the reverse draw salt $(\mathrm{NaCl})$ flux also led to a decrease in the forward hydrogen ion flux as observed in Figure 1. It is likely that the reverse flux of $\mathrm{Cl}^{-}$was hindered by an enhanced electrostatic interaction with the more negatively charged humic acid fouling layer. To maintain the electroneutrality of the feed solution, the forward diffusion of hydrogen ions was coupled with the reverse permeate of draw solution $\mathrm{Na}^{+}$(Hancock and Cath 2009, Xie et al. 2012b). Therefore, the forward hydrogen ion flux also decreased with the decrease in the reverse draw salt flux as the concentration of calcium increased from 0 to $4 \mathrm{mM}$.

\section{[Figure 4]}

\subsection{Impact of fouling on PhAC permeation}

\subsubsection{Role of calcium and humic acid fouling}

Permeation of the neutral carbamazepine decreased substantially from $23 \%$ under clean membrane conditions to $14 \%$ when humic acid was introduced to a feed solution that did not contain calcium (Figure 5). The molecular width of carbamazepine is $0.529 \mathrm{~nm}$ (Table 1) while the membrane pore diameter is $0.74 \mathrm{~nm}$ (Xie et al. 2012a). Thus, it is possible that the hydrated humic acid fouling layer could have hindered solute transport through the membrane pore, thereby reducing the permeation of carbamazepine as humic acid fouling occurred. Hindrance of carbamazepine permeation caused by the hydrated humic acid fouling layer was further enhanced as calcium was introduced to the feed solution, (which also led to 
an increase in the deposition of humic acid on the membrane surface as reported in section 3.1). Indeed, carbamazepine permeation decreased further to $3 \%$ as the calcium concentration in the feed solution increased from 0 to $4 \mathrm{mM}$ (Figure 5).

The molecular width of sulfamethoxazole is slightly larger than that of carbamazepine. More importantly, at $\mathrm{pH}$ 6.5, both the membrane and more than $90 \%$ of sulfamethoxazole molecules are negatively charged (Figure 4). Thus, in addition to steric hindrance, electrostatic interaction also plays an important role in the rejection of this compound (Xie et al. 2012b). As a result, permeation of the charged sulfamethoxazole was considerably smaller than that of the neutral carbamazepine. The permeation of the negatively charged sulfamethoxazole decreased from $10 \%$ in the clean matrix to $6.1 \%$ in the humic acid matrix with no calcium in solution (Figure 5). The permeation of sulfamethoxazole decreased further to $1.2 \%$ as the deposition of humic acid on the membrane surface increased due to the introduction of $4 \mathrm{mM}$ calcium to the feed solution. It is noteworthy that reduction in the permeation of both carbamazepine and sulfamethoxazole correlates very well with the decrease in the membrane salt $(\mathrm{NaCl})$ permeability coefficient reported in section 3.1. Coefficients of determination $\left(R^{2}\right)$ of the linear regression between the membrane salt $(\mathrm{NaCl})$ permeability coefficient and the reduction in carbamazepine and sulfamethoxazole permeation were 0.996 and 0.997 , respectively.

\section{[Figure 5]}

353

354

355

356

357

\subsubsection{Role of reverse draw salt flux}

To provide further insight into the impact of the humic acid fouling layer on the passage of carbamazepine and sulfamethoxazole through the $\mathrm{FO}$ membrane, $\mathrm{MgSO}_{4}$, urea, and glucose were also used as the draw solutes, in addition to $\mathrm{NaCl}$, to obtain a range of reverse draw solute fluxes (Figure 6). In a clean matrix, reverse draw solute flux could hinder the forward diffusion of neutral solutes, through a phenomenon known as 'retarded forward diffusion', thereby reducing their permeation through the FO membrane (Xie et al. 2012a). In agreement with the retarded forward diffusion phenomenon, permeation of neutral carbamazepine in the clean matrix is inversely proportional to the reverse draw solute flux (Figure 6), which is in the order of urea $<\mathrm{NaCl}<$ glucose $<\mathrm{MgSO}_{4}$ (Figure 7) when these draw solutes were used in FO experiments.

Different types and degrees of reverse draw solute flux resulted in varying amounts of humic acid deposited on the membrane surface. The amount of humic acid deposited on the 
membrane surface for the fouling experiments with the four types of draw solutes was in the following order: $\mathrm{NaCl}>\mathrm{MgSO}_{4} \approx$ urea $\approx$ glucose (Figure 6). Reverse transport of ionic $\mathrm{NaCl}$ draw solute likely elevated the localized ionic strength in the fouling layer and led to further aggregation of humic acid foulant, thereby promoting the deposition of humic acid (Tang et al. 2011).

Varying deposition of humic acid on the membrane surface using four types of draw solutes led to differing reductions in the permeation of carbamazepine and sulfamethoxazole. The reductions occurred in the following order: $\mathrm{NaCl}>\mathrm{MgSO}_{4} \approx$ urea $\approx$ glucose (Figure 7 ), which was the same as the order of draw solutes observed when measuring the amount of humic acid deposition on the membrane surface (Figure 6). This observation was consistent with our hypothesis that the hydrated humic acid fouling layer hindered feed solute transport through the membrane pores, thereby reducing their permeation.

\section{[Figure 6]}

\section{[Figure 7]}

\subsection{PhAC permeation after physical cleaning of the membrane}

Membrane cleaning was conducted by increasing the cross-flow velocity from 9 to 18 $\mathrm{cm} / \mathrm{s}$. Because of the low hydraulic resistance and loose structure of the humic acid cake layer, which is a characteristic of the fouling layer in FO (Mi and Elimelech 2008), it is not surprising that the humic acid cake layer was fully removed by the increase in the shearing rate. This physical cleaning restored the permeation of carbamazepine and sulfamethoxazole as well as the reverse salt $(\mathrm{NaCl})$ flux to those of the virgin (clean) membrane (Figure 8). The reversible fouling behaviour observed here confirms a weak adhesion of humic acid to the membrane surface (Mi and Elimelech 2008) and suggests that humic acid did not penetrate into the membrane pores.

\section{[Figure 8]}

\section{Conclusion}

Results reported here indicate that calcium in the feed solution promoted the deposition of humic acid onto the membrane surface. Higher deposition of humic acid was also observed when $\mathrm{NaCl}$ was used as the draw solute due to an increase in ionic strength at the membrane interface in comparison to $\mathrm{MgSO}_{4}$, glucose, and urea, which exhibited a negligible reverse solute flux or are organic based. The increase in humic acid deposition on 
the membrane surface led to a substantial decrease in the membrane salt $(\mathrm{NaCl})$ permeability coefficient but did not result in a significant decrease in the membrane pure water permeability coefficient. The decrease in carbamazepine and sulfamethoxazole permeation as the deposition of humic acid increased, which correlated well with the decrease in the membrane salt $(\mathrm{NaCl})$ permeability coefficient. It is hypothesized that the hydrated humic acid fouling layer hindered solute transport through the membrane pores and enhanced steric hindrance, but not the diffusion of water. Results reported here also indicate that the humic acid did not penetrate into the membrane pores.

\section{Acknowledgments}

We acknowledge the doctoral scholarship provided by the University of Wollongong to Ming Xie to support his PhD study. Hydration Technology Innovations is thanked for the provision of membrane samples.

\section{References}

Achilli, A., Cath, T.Y., Marchand, E.A. and Childress, A.E. (2009) The forward osmosis membrane bioreactor: A low fouling alternative to MBR processes. Desalination 239(1-3), $10-21$.

Alturki, A., McDonald, J., Khan, S.J., Hai, F.I., Price, W.E. and Nghiem, L.D. (2012) Performance of a novel osmotic membrane bioreactor (OMBR) system: Flux stability and removal of trace organics. Bioresource Technology 113, 201-206.

Alturki, A.A., McDonald, J.A., Khan, S.J., Price, W.E., Nghiem, L.D. and Elimelech, M. (2013) Removal of trace organic contaminants by the forward osmosis process. Separation and Purification Technology 103, 258-266.

Basile, T., Petrella, A., Petrella, M., Boghetich, G., Petruzzelli, V., Colasuonno, S. and Petruzzelli, D. (2011) Review of Endocrine-Disrupting-Compound Removal Technologies in Water and Wastewater Treatment Plants: An EU Perspective. Industrial \& Engineering Chemistry Research 50(14), 8389-8401.

Boo, C., Lee, S., Elimelech, M., Meng, Z. and Hong, S. (2012) Colloidal fouling in forward osmosis: Role of reverse salt diffusion. Journal of Membrane Science 390-391, 277-284.

Carballa, M., Omil, F., Lema, J.M., Llompart, M.a., García-Jares, C., Rodríguez, I., Gómez, M. and Ternes, T. (2004) Behavior of pharmaceuticals, cosmetics and hormones in a sewage treatment plant. Water Research 38(12), 2918-2926.

Cath, T.Y., Childress, A.E. and Elimelech, M. (2006) Forward osmosis: Principles, applications, and recent developments. Journal of Membrane Science 281(1-2), 70-87.

Cath, T.Y., Elimelech, M., McCutcheon, J.R., McGinnis, R.L., Achilli, A., Anastasio, D., Brady, A.R., Childress, A.E., Farr, I.V., Hancock, N.T., Lampi, J., Nghiem, L.D., Xie, M. and Yip, N.Y. (2013) Standard Methodology for Evaluating Membrane Performance in Osmotically Driven Membrane Processes. Desalination 312, 31-38. 
434 Cohen-Tanugi, D. and Grossman, J.C. (2012) Water Desalination across Nanoporous 435 Graphene. Nano Letters 12(7), 3602-3608.

436 Elimelech, M., Chen, W.H. and Waypa, J.J. (1994) Measuring the zeta (electrokinetic) 437 potential of reverse osmosis membranes by a streaming potential analyzer. Desalination 95(3), $438 \quad 269-286$.

439 Elimelech, M. and Phillip, W.A. (2011) The Future of Seawater Desalination: Energy, 440 Technology, and the Environment. Science 333(6043), 712-717.

441 Hancock, N.T. and Cath, T.Y. (2009) Solute Coupled Diffusion in Osmotically Driven 442 Membrane Processes. Environmental Science \& Technology 43(17), 6769-6775.

443 Hancock, N.T., Phillip, W.A., Elimelech, M. and Cath, T.Y. (2011a) Bidirectional 444 Permeation of Electrolytes in Osmotically Driven Membrane Processes. Environmental 445 Science \& Technology 45(24), 10642-10651.

446 Hancock, N.T., Xu, P., Heil, D.M., Bellona, C. and Cath, T.Y. (2011b) Comprehensive 447 Bench- and Pilot-Scale Investigation of Trace Organic Compounds Rejection by Forward 448 Osmosis. Environmental Science \& Technology 45(19), 8483-8490.

449 Hoover, L.A., Phillip, W.A., Tiraferri, A., Yip, N.Y. and Elimelech, M. (2011) Forward with 450 Osmosis: Emerging Applications for Greater Sustainability. Environmental Science \& 451 Technology 45(23), 9824-9830.

452 Jin, X., Shan, J., Wang, C., Wei, J. and Tang, C.Y. (2012a) Rejection of pharmaceuticals by 453 forward osmosis membranes. Journal of Hazardous Materials 227-228, 55-61.

454 Jin, X., She, Q., Ang, X. and Tang, C.Y. (2012b) Removal of boron and arsenic by forward 455 osmosis membrane: Influence of membrane orientation and organic fouling. Journal of 456 Membrane Science 389, 182-187.

457 McCutcheon, J.R. and Elimelech, M. (2008) Influence of membrane support layer 458 hydrophobicity on water flux in osmotically driven membrane processes. Journal of 459 Membrane Science 318(1-2), 458-466.

460 Mi, B. and Elimelech, M. (2008) Chemical and physical aspects of organic fouling of forward 461 osmosis membranes. Journal of Membrane Science 320(1-2), 292-302.

$462 \mathrm{Ng}, \mathrm{H.Y}$. and Elimelech, M. (2004) Influence of colloidal fouling on rejection of trace 463 organic contaminants by reverse osmosis. Journal of Membrane Science 244(1-2), 215-226.

464 Nghiem, L.D. and Hawkes, S. (2007) Effects of membrane fouling on the nanofiltration of 465 pharmaceutically active compounds (PhACs): Mechanisms and role of membrane pore size. 466 Separation and Purification Technology 57(1), 176-184.

467 Nghiem, L.D., Vogel, D. and Khan, S. (2008) Characterising humic acid fouling of 468 nanofiltration membranes using bisphenol A as a molecular indicator. Water Research 42(15), 469 4049-4058.

470 Parida, V. and Ng, H.Y. (2013) Forward osmosis organic fouling: Effects of organic loading, 471 calcium and membrane orientation. Desalination 312, 88-98.

472 Phillip, W.A., Yong, J.S. and Elimelech, M. (2010) Reverse Draw Solute Permeation in 473 Forward Osmosis: Modeling and Experiments. Environmental Science \& Technology 44(13), $474 \quad 5170-5176$. 
Plakas, K.V., Karabelas, A.J., Wintgens, T. and Melin, T. (2006) A study of selected herbicides retention by nanofiltration membranes-The role of organic fouling. Journal of Membrane Science 284(1-2), 291-300.

478 Schwarzenbach, R.P., Escher, B.I., Fenner, K., Hofstetter, T.B., Johnson, C.A., von Gunten, 479 U. and Wehrli, B. (2006) The Challenge of Micropollutants in Aquatic Systems. Science 480 313(5790), 1072-1077.

481

482

483

484

485

486

487

488

489

490

491

492

493

494

495

496

497

498

499

500

501

502

503

504

505

506

507

508

509

510

511

512

513

514

515

516

517
Shaffer, D.L., Yip, N.Y., Gilron, J. and Elimelech, M. (2012) Seawater desalination for agriculture by integrated forward and reverse osmosis: Improved product water quality for potentially less energy. Journal of Membrane Science 415-416, 1-8.

Shannon, M.A., Bohn, P.W., Elimelech, M., Georgiadis, J.G., Marinas, B.J. and Mayes, A.M. (2008) Science and technology for water purification in the coming decades. Nature 452(7185), 301-310.

Simon, A., Price, W. and Nghiem, L. (2011) Implications of membrane fouling toward the removal of the pharmaceutical sulfamethoxazole by nanofiltration processes. Journal of Zhejiang University SCIENCE A 12(8), 575-582.

Sutzkover, I., Hasson, D. and Semiat, R. (2000) Simple technique for measuring the concentration polarization level in a reverse osmosis system. Desalination 131(1-3), 117-127.

Tang, C.Y., Chong, T.H. and Fane, A.G. (2011) Colloidal interactions and fouling of NF and RO membranes: A review. Advances in Colloid and Interface Science 164(1-2), 126-143.

Valladares Linares, R., Yangali-Quintanilla, V., Li, Z. and Amy, G. (2011) Rejection of micropollutants by clean and fouled forward osmosis membrane. Water Research 45(20), 6737-6744.

Vogel, D., Simon, A., Alturki, A.A., Bilitewski, B., Price, W.E. and Nghiem, L.D. (2010) Effects of fouling and scaling on the retention of trace organic contaminants by a nanofiltration membrane: The role of cake-enhanced concentration polarisation. Separation and Purification Technology 73(2), 256-263.

Wang, Y., Combe, C. and Clark, M.M. (2001) The effects of pH and calcium on the diffusion coefficient of humic acid. Journal of Membrane Science 183(1), 49-60.

Xie, M., Nghiem, L.D., Price, W.E. and Elimelech, M. (2012a) Comparison of the removal of hydrophobic trace organic contaminants by forward osmosis and reverse osmosis. Water Research 46(8), 2683-2692.

Xie, M., Price, W.E. and Nghiem, L.D. (2012b) Rejection of pharmaceutically active compounds by forward osmosis: Role of solution $\mathrm{pH}$ and membrane orientation. Separation and Purification Technology 93, 107-114.

Xu, P., Drewes, J.E., Kim, T.-U., Bellona, C. and Amy, G. (2006) Effect of membrane fouling on transport of organic contaminants in NF/RO membrane applications. Journal of Membrane Science 279(1-2), 165-175.

Yangali-Quintanilla, V., Li, Z., Valladares, R., Li, Q. and Amy, G. (2011) Indirect desalination of Red Sea water with forward osmosis and low pressure reverse osmosis for water reuse. Desalination 280(1-3), 160-166.

Yong, J.S., Phillip, W.A. and Elimelech, M. (2012) Coupled reverse draw solute permeation and water flux in forward osmosis with neutral draw solutes. Journal of Membrane Science 392-393, 9-17. 
518 Zhao, S., Zou, L., Tang, C.Y. and Mulcahy, D. (2012) Recent developments in forward 519 osmosis: Opportunities and challenges. Journal of Membrane Science 396, 1-21. 
521 Table 1: Key physicochemical properties of model PhACs used in this study

Pharmaceutical Carbamazepine

\begin{tabular}{|c|c|c|c|}
\hline Molecular weight (Da & & 236.3 & 253.3 \\
\hline $\mathrm{p} K_{\mathrm{a}}{ }^{\mathrm{a}}$ & & 9.73 & $1.7 ; 5.8$ \\
\hline $\log K_{\mathrm{ow}}{ }^{\mathrm{a}}$ & & 2.45 & 0.89 \\
\hline \multirow{3}{*}{ Molecular dimensions (nm) ${ }^{b}$} & Length & 0.891 & 1.031 \\
\hline & Width & 0.529 & 0.587 \\
\hline & Depth & 0.507 & 0.526 \\
\hline
\end{tabular}

\footnotetext{
${ }^{\mathrm{a}}$ From the SciFinder Scholar (ACS) database.

${ }^{\mathrm{b}}$ Molecular dimensions were calculated using Molecular Modelling Pro Version 6.3.3 (Chem SW Inc.).
} 
526 Figure 1: Reverse salt $(\mathrm{NaCl})$ and hydrogen ion fluxes and the deposition of humic acid onto the membrane surface as a function of calcium in the feed solution. The deposition of humic acid was determined by mass balance calculation. The experimental conditions were as follows: initial concentrations of carbamazepine and sulfamethoxazole in the feed $=500 \mu \mathrm{g} / \mathrm{L}$, initial concentration of humic acid $=50 \mathrm{mg} / \mathrm{L}$, initial feed solution $\mathrm{pH}=6.5$, the background electrolyte contained $20 \mathrm{mM} \mathrm{NaCl}, 1 \mathrm{mM} \mathrm{NaHCO}_{3}$, and varying concentrations of $\mathrm{Ca}^{2+}$, draw solution $=0.5 \mathrm{M} \mathrm{NaCl}$, cross-flow rate $=1 \mathrm{~L} / \mathrm{min}$ for both sides (corresponding to the cross-flow velocity of $9 \mathrm{~cm} / \mathrm{s}$ ), and temperatures of the feed and draw solutions $=25 \pm 1{ }^{\circ} \mathrm{C}$. Error bar represents standard deviation from duplicate runs at the specified experimental conditions.

Figure 2: Pure water and salt $(\mathrm{NaCl})$ permeability coefficients in clean and humic acid matrices with calcium concentrations from 0 to $4 \mathrm{mM}$. Error bar represents standard deviation from duplicate experiments.

539 Figure 3: The permeate water flux of humic acid fouling in forward osmosis (FO). FO experimental conditions: the initial feed $\mathrm{pH}=6.5$ and the feed solution contained $50 \mathrm{mg} / \mathrm{L}$ humic acid in a background electrolyte $\left(20 \mathrm{mM} \mathrm{NaCl}, 1 \mathrm{mM} \mathrm{NaHCO}_{3}\right.$, and varying concentrations of $\mathrm{Ca}^{2+}$ from 0 to $4 \mathrm{mM}$ ). Draw solution $=0.5 \mathrm{M} \mathrm{NaCl}$. Cross-flow rate $=1$ $\mathrm{L} / \mathrm{min}$ (corresponding to the cross-flow velocity of $9 \mathrm{~cm} / \mathrm{s}$ ). Temperatures of feed and draw solutions were $25 \pm 1^{\circ} \mathrm{C}$.

545 Figure 4: Zeta potential of virgin and humic acid-fouled FO membranes. A humic acid546 fouled membrane was dried in a desiccator and then soaked in Milli-Q water for 24 hours 547 prior to the measurement. The humic acid fouling experimental conditions were described in

548 Figure 1. Error bar represents the standard deviation of duplicate measurements of two membrane samples at the specified experimental conditions.

550 Figure 5: Permeation of carbamazepine and sulfamethoxazole in the clean matrix and in the humic acid matrix at varying concentrations of $\mathrm{Ca}^{2+}$. The experimental conditions were described in Figure 1. The error bar represents the standard deviation from duplicate experiments.

554 Figure 6: The flux of reverse draw solute and the deposition of humic acid in clean and 555 humic acid matrices using 0.5 M NaCl, $2.5 \mathrm{M} \mathrm{MgSO}_{4}$, $3 \mathrm{M}$ glucose, and $3.5 \mathrm{M}$ urea as draw 556 solutions, respectively. The experimental conditions were as follows: the initial 
557 concentrations of carbamazepine and sulfamethoxazole in the feed $=500 \mu \mathrm{g} / \mathrm{L}$, initial feed $558 \mathrm{pH}=6.5$, initial humic acid concentration $=50 \mathrm{mg} / \mathrm{L}$, the background electrolyte solution 559 contained $20 \mathrm{mM} \mathrm{NaCl}, 1 \mathrm{mM} \mathrm{NaHCO}_{3}$, and $2 \mathrm{mM} \mathrm{Ca}^{2+}$. Varying draw solutions of $0.5 \mathrm{M}$ $560 \mathrm{NaCl}, 2.5 \mathrm{M} \mathrm{MgSO}_{4}, 3 \mathrm{M}$ glucose, and 3.5 $\mathrm{M}$ urea were used to induce the same initial water 561 flux. The feed and draw solution temperature was $25 \pm 1^{\circ} \mathrm{C}$. Cross-flow rate $=1 \mathrm{~L} / \mathrm{min}$ for 562 both sides (corresponding to the cross-flow velocity of $9 \mathrm{~cm} / \mathrm{s}$ ).

563 Figure 7: Comparison of permeation of (a) sulfamethoxazole and (b) carbamazepine using 564 varying types and concentrations of draw solutes in FO. Other experimental conditions were 565 described in Figure 6.

566 Figure 8: Comparison of permeation of sulfamethoxazole and carbamazepine and reverse 567 salt $(\mathrm{NaCl})$ flux among virgin membrane, humic acid fouled membrane, and physically 568 cleaned membrane at an initial feed $\mathrm{pH}$ of 6.5. Experimental conditions for the physically 569 cleaned membrane were: initial concentrations of sulfamethoxazole and carbamazepine in the 570 feed $=500 \mu \mathrm{g} / \mathrm{L}$, initial $\mathrm{pH}=6.5$, the background electrolyte contained $20 \mathrm{mM} \mathrm{NaCl}$ and 1 $571 \mathrm{mM} \mathrm{NaHCO}$, draw solution $=0.5 \mathrm{M} \mathrm{NaCl}$, cross-flow rate $=1 \mathrm{~L} / \mathrm{min}$ for both sides 572 (corresponding to the cross-flow velocity of $9 \mathrm{~cm} / \mathrm{s}$ ), temperatures of the feed and draw 573 solutions $=25 \pm 1^{\circ} \mathrm{C}$. 


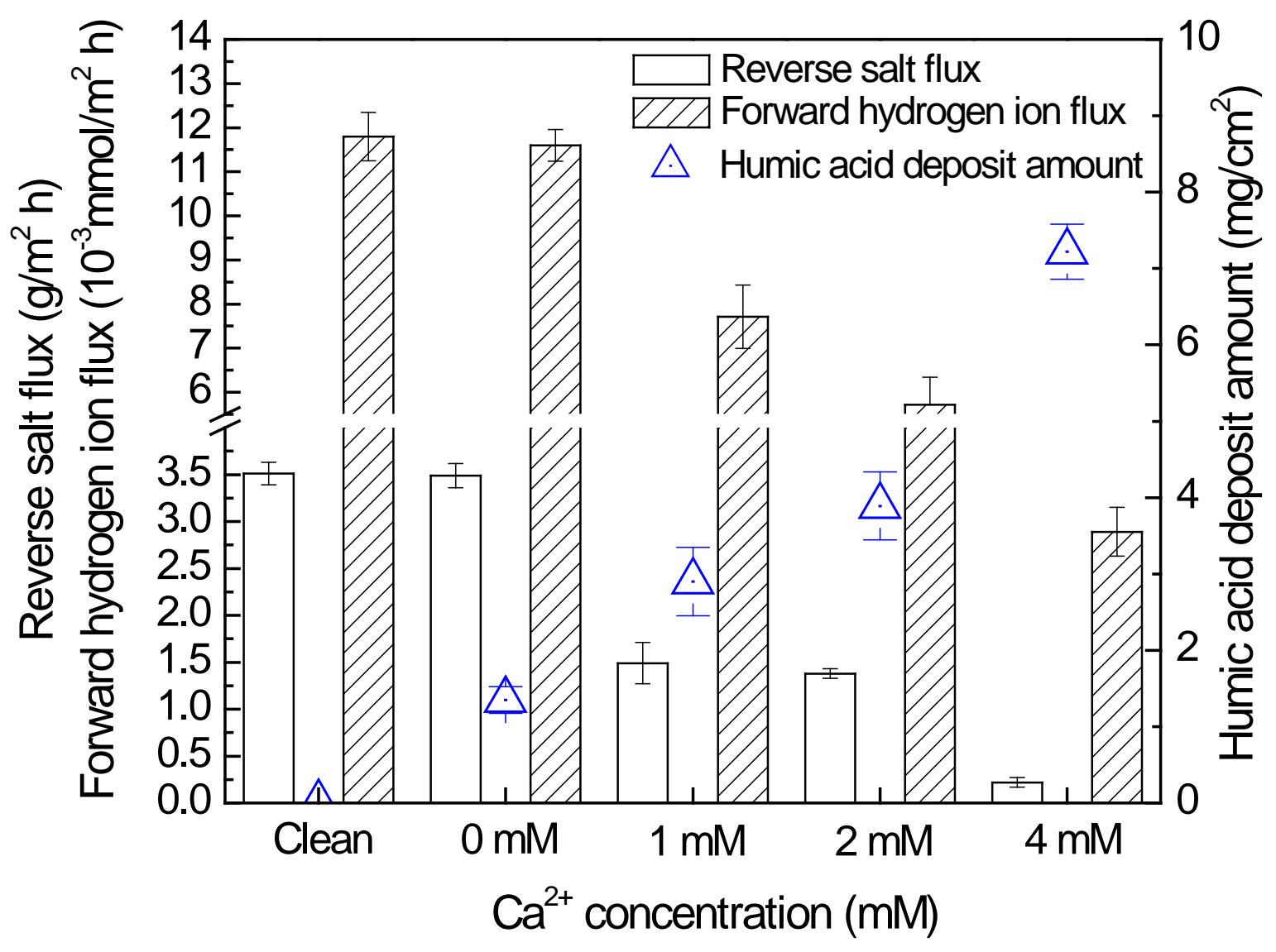

574

575 Figure 1 


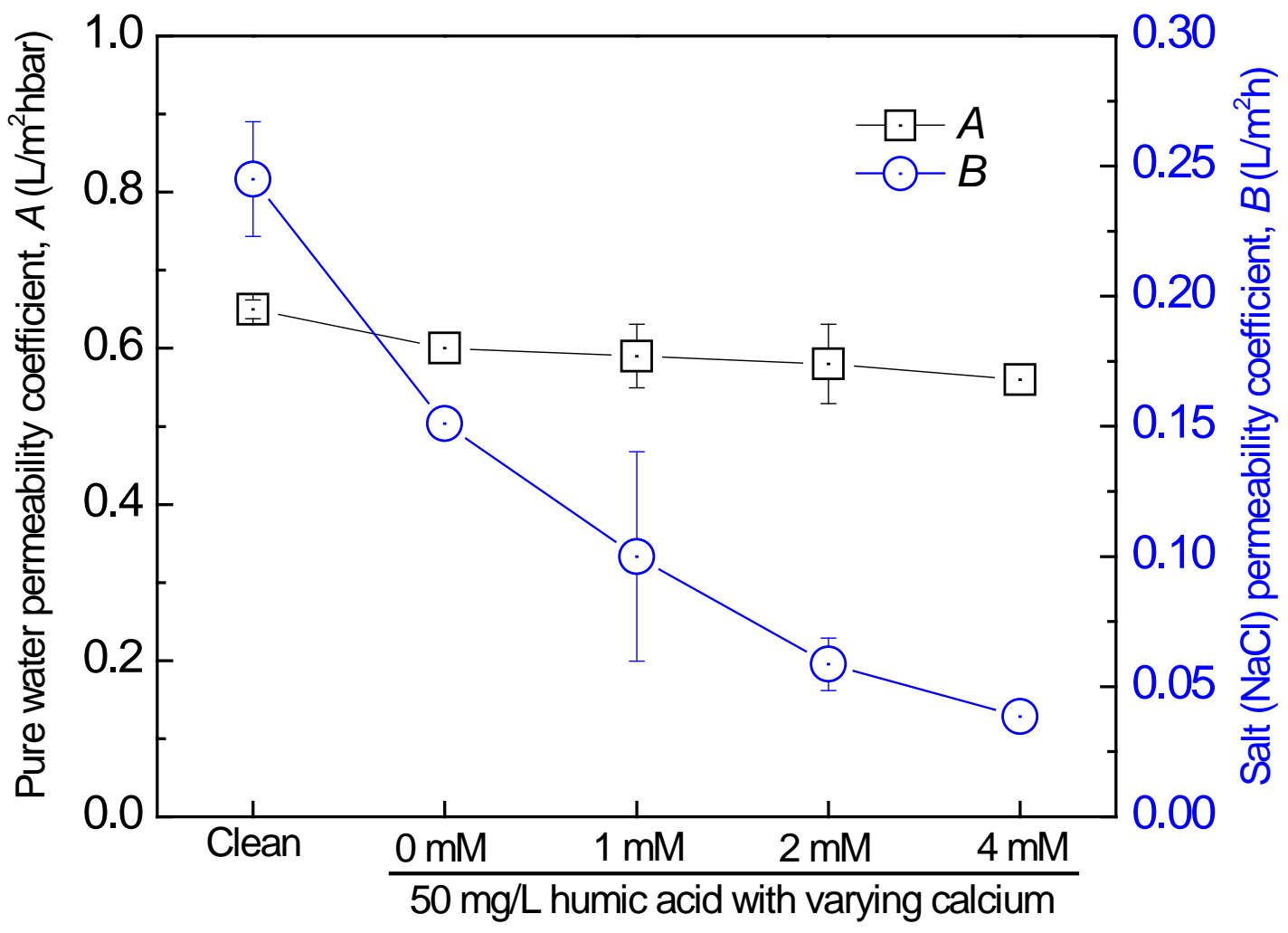

576

$577 \quad$ Figure 2 


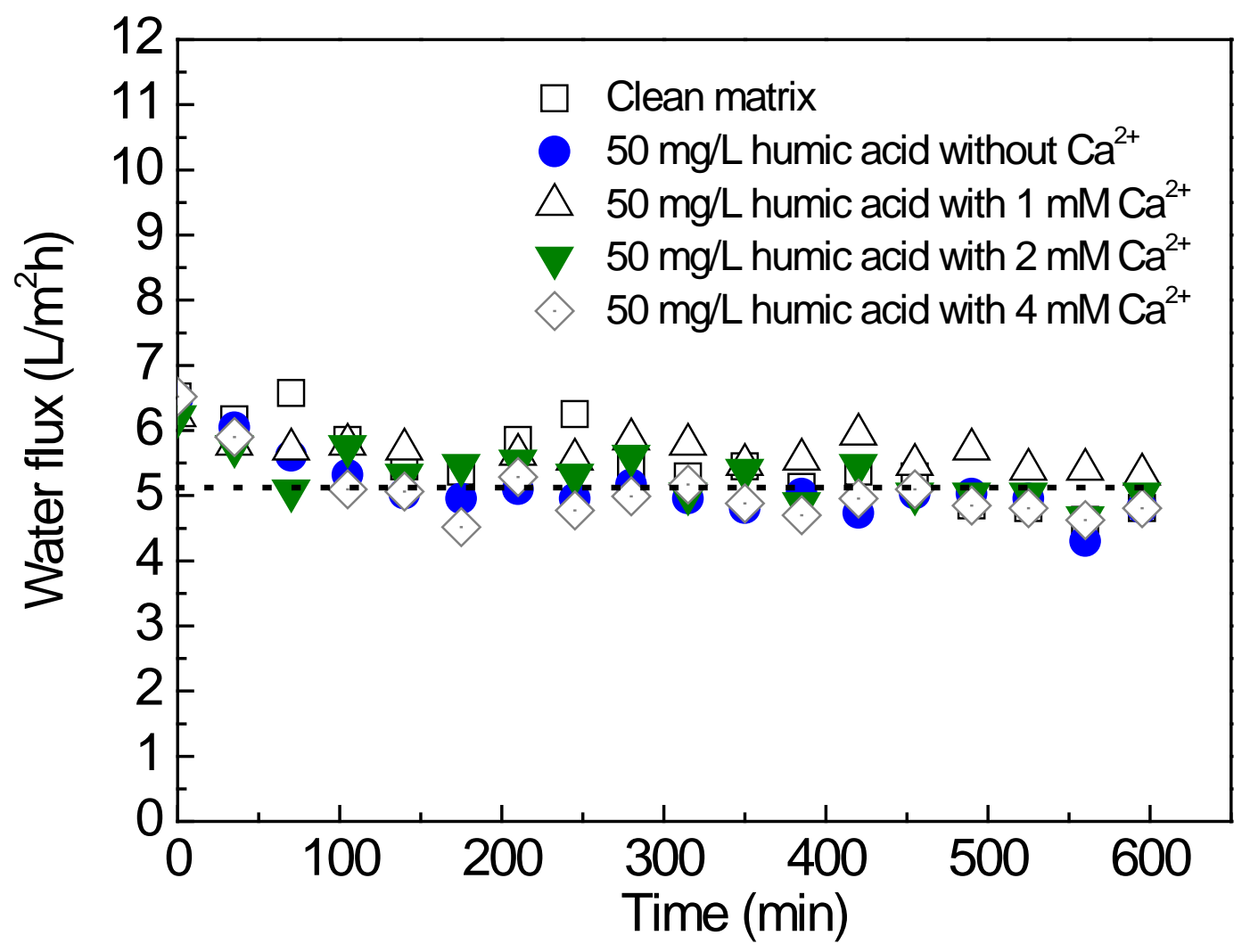

578

$579 \quad$ Figure 3 


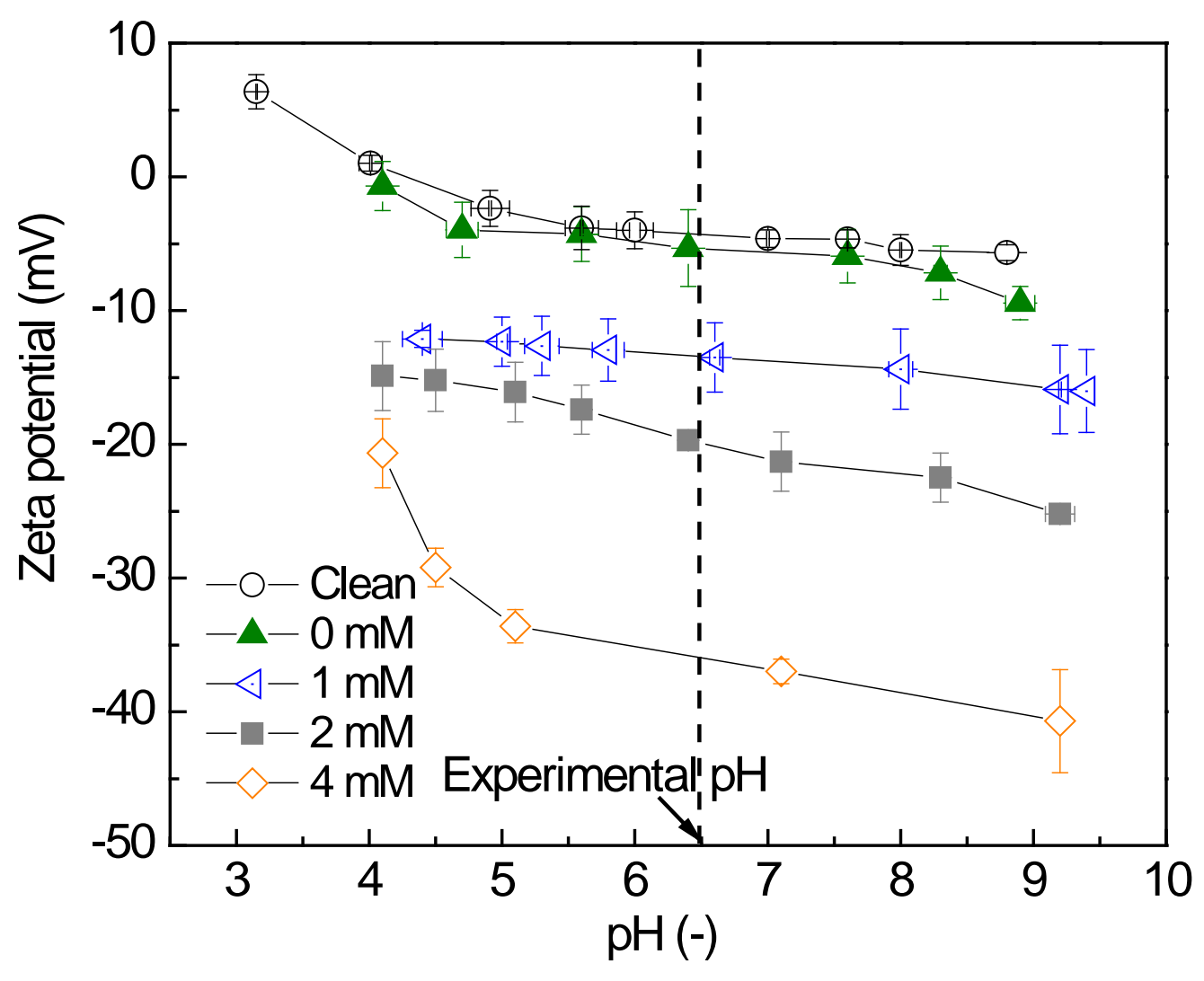

580

$581 \quad$ Figure 4 


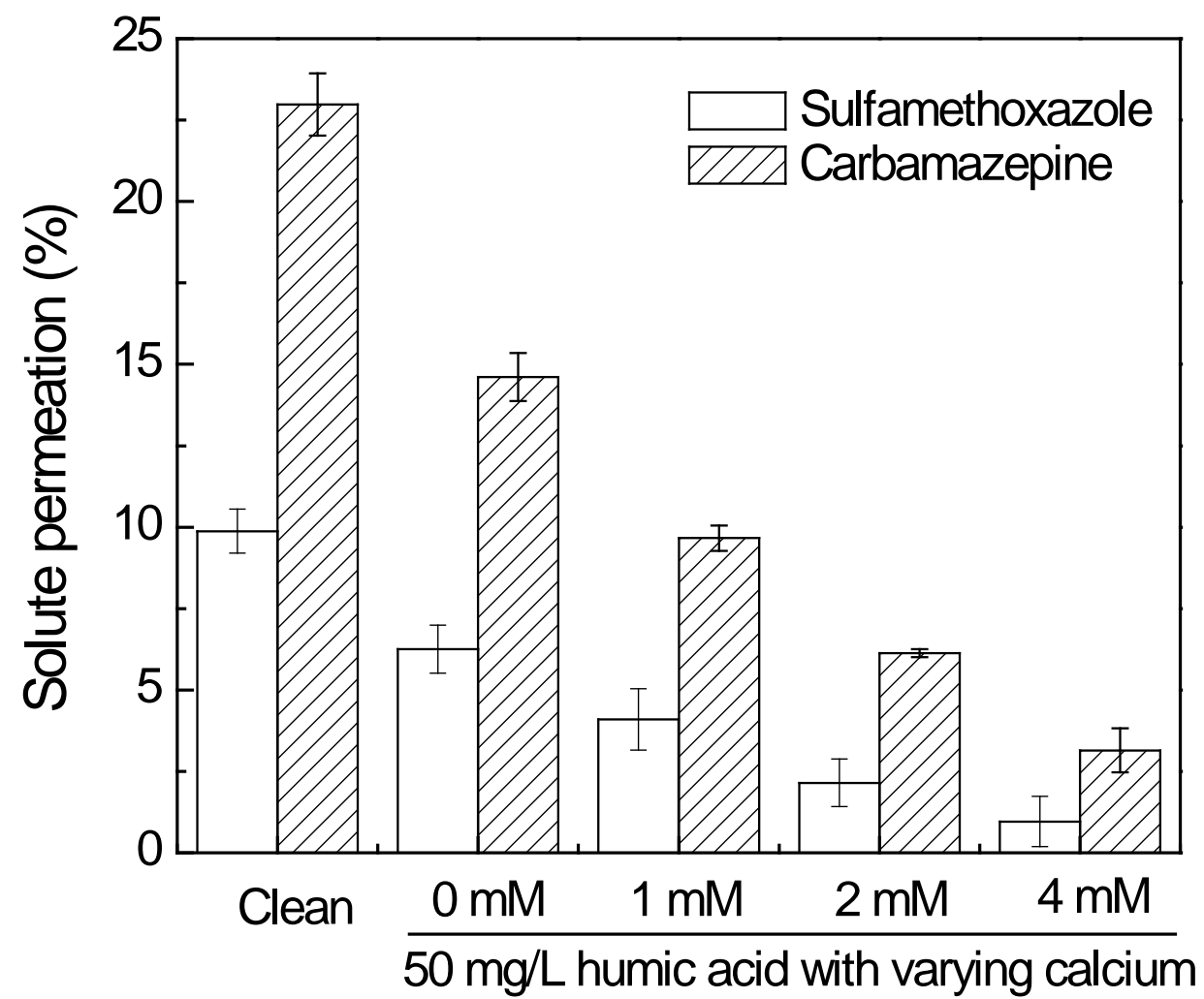

$583 \quad$ Figure 5 


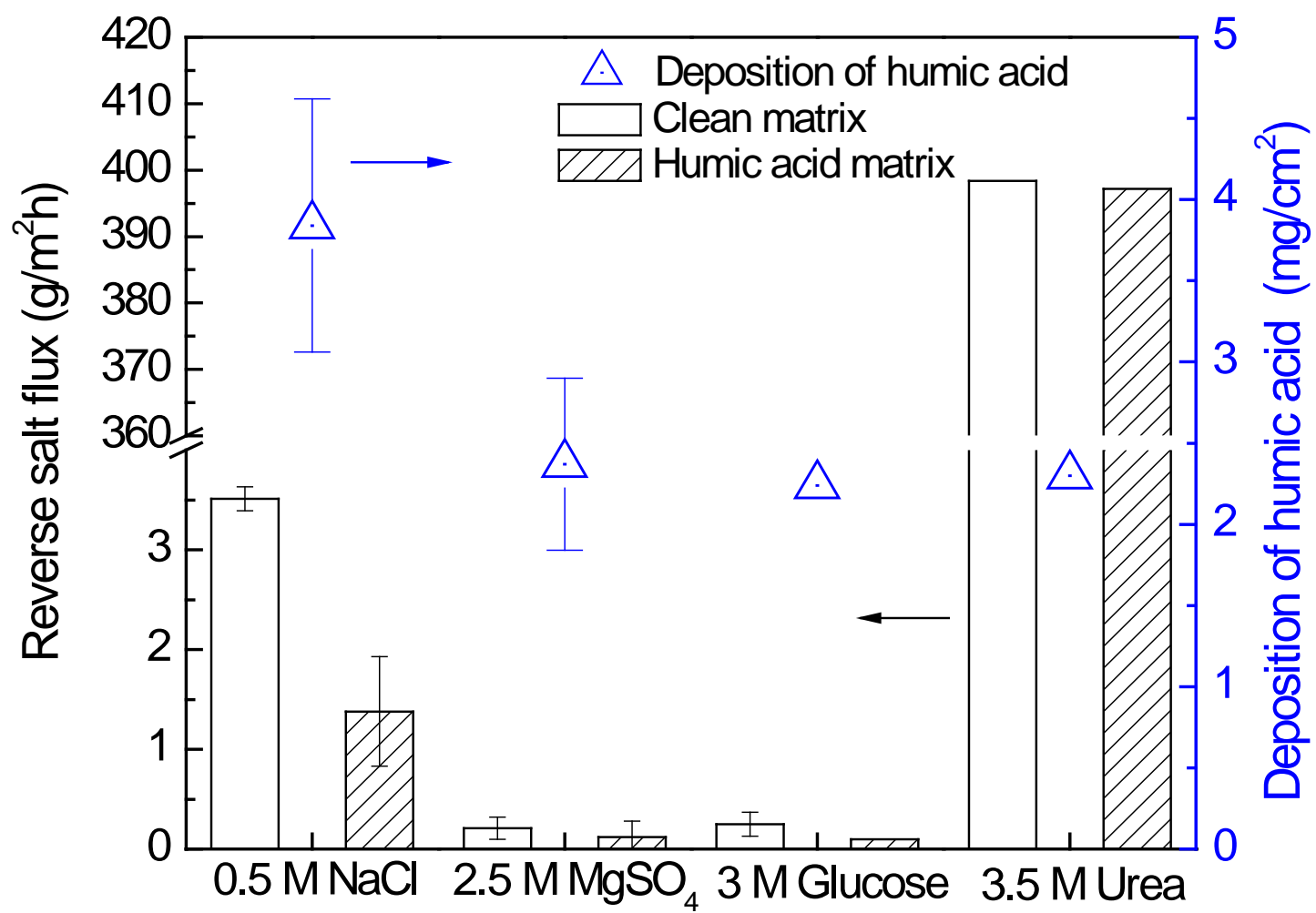

$585 \quad$ Figure 6 

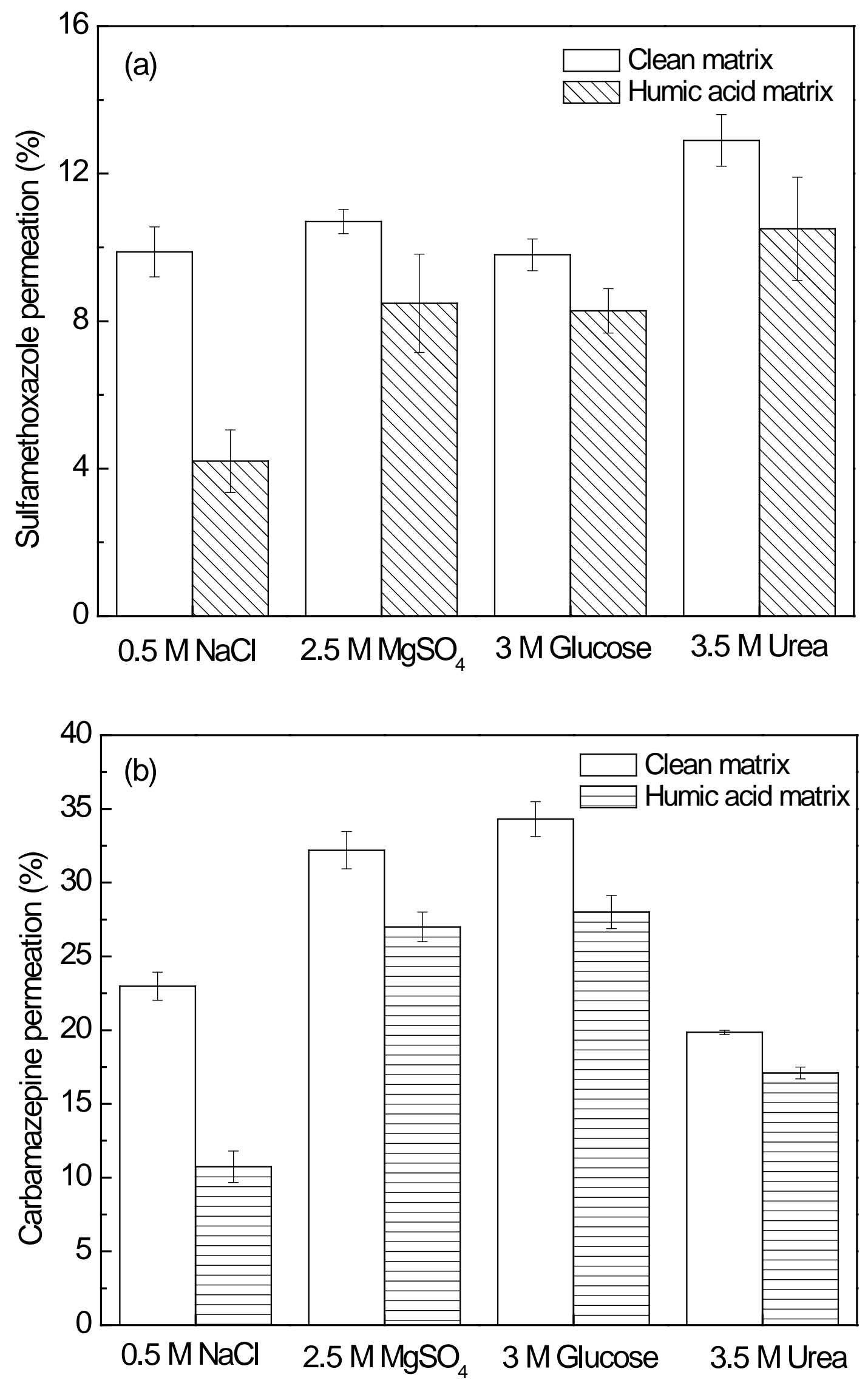

$587 \quad$ Figure 7 


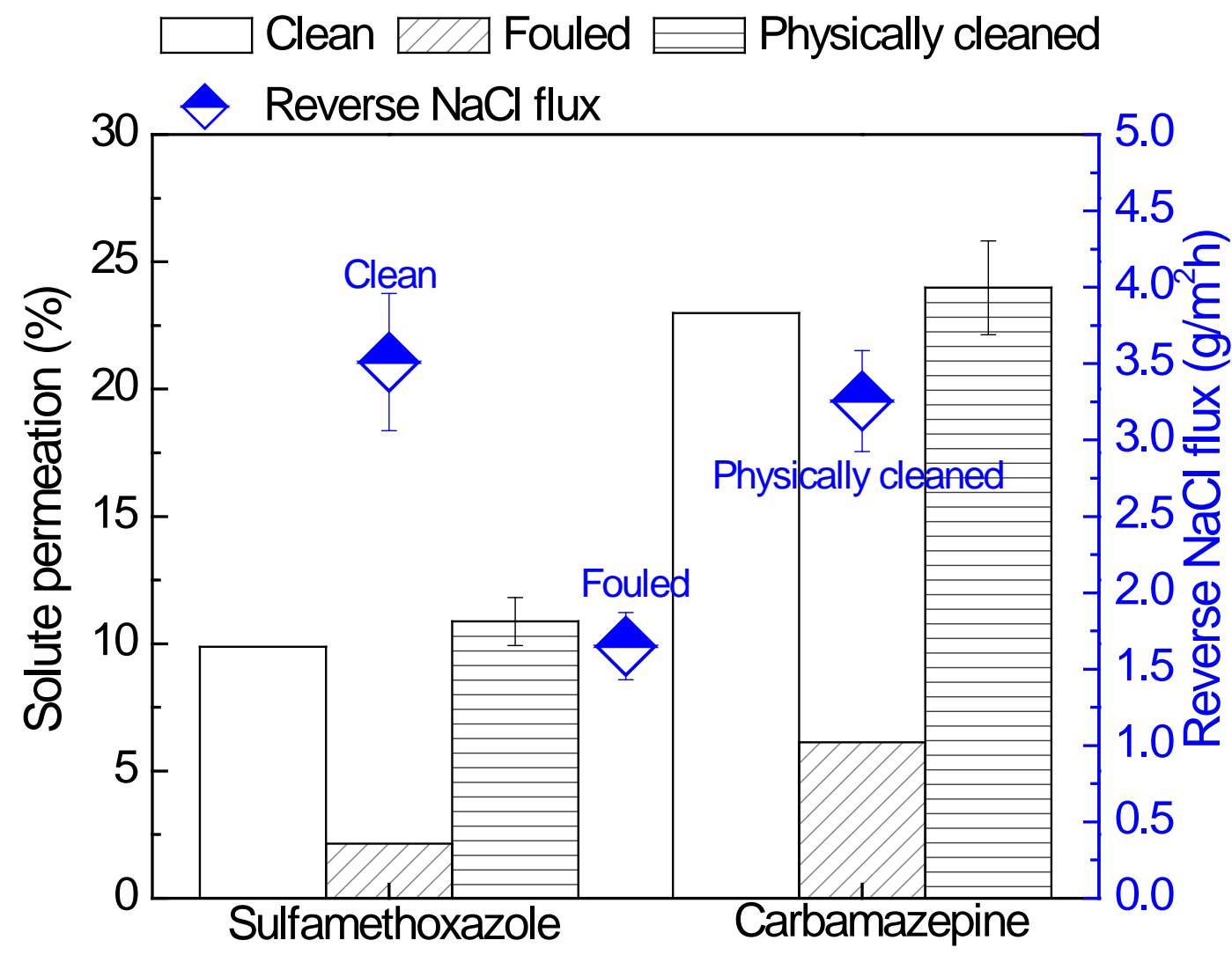

$589 \quad$ Figure 8 